\title{
YELLOW FEVER, DENGUE FEVER AND WEST NILE VIRUSES CO-CIRCULATION IN OGBOMOSO
}

\author{
${ }^{1,2}$ Oladipo E.K., ${ }^{1}$ Awoyelu E.H., ${ }^{1}$ Oloke J.K. \\ ${ }^{1}$ Department of Pure and Applied Biology (Microbiology/Virology Unit), Ladoke Akintola University, \\ P.M.B 4000, Ogbomoso, Nigeria \\ ${ }^{2}$ Department of Microbiology, Adeleke University Ede, Osun State, Nigeria
}

\begin{abstract}
Arboviruses are an emerging threat of significant impact on human health and well-being. With increasing proportion of the world living in urban environments, inadvertently, there is the creation of better habitats for vector species. This study is aimed at establishing the occurrence of arboviruses within Ogbomoso, with a view to providing baseline data for further study. Ninety-three plasma samples from consenting individuals in the age range 1-75 years were collected and screened for IgM to dengue fever (DENV), West Nile (WNV) and yellow fever (YFV) viruses using third generation Enzyme Linked Immuno-Sorbent Assay (WKEA Med Supplies Corp, China) kits. An overall prevalence of 52.7\% (49/93) were recorded from the recruited individuals. IgM antibodies to Dengue, Yellow fever and West Nile viruses were found in 16/49 (17.2\%), 16/49 (17.2\%) and 17/49 (18.3\%), respectively. High prevalence were recorded in the age groups 16-30, 31-45 and 61-75 years. Gender analysis of the positive samples showed higher prevalence among females than males. The result also showed high prevalence in urban settings than rural settings for DENV and WNV, however, for YNF, higher prevalence was found in the rural area. The prevalence of dual and trio arboviral infection showed $17.2 \%$ and $11.8 \%$ respectively. This study confirms the circulation of Dengue fever, Yellow fever and West Nile viruses in Ogbomoso and therefore suggest the need for public awareness on vector control.
\end{abstract}

Keywords: Yellow fever, Dengue, West Nile, Ogbomoso, IgM

\section{Introduction}

Arboviruses (arthropod-borne viruses), belonging to the genus Flavivirus, family Flaviviridae, are transmitted to humans primarily through the bites of mosquitoes and ticks (Lindsey et al., 2014). With regards to disease impact, Flaviviruses include dengue virus (DENV), yellow fever virus (YFV), West Nile virus (WNV), etc. (Chisom et al., 2017). Depending on specific vectors and different natural hosts, flaviviruses have distinct geographical distributions. There is heavy build-up of mosquitoes in the tropics (Adeleke et al., 2010).

Several factors that favour the spread and transmission of arboviruses include human movement, climatic and environmental factors. Climatic factors, most especially temperature, relative humidity and rainfall patterns are strong environmental drivers of vector-borne disease transmission which in turn determines the environmental suitability or potential for viral transmission (Kanfui, 2017). Activities in the urban and rural areas are of particular concern in the transmission of mosquito-borne diseases (Monath, 1994). With the relatively recent long distance travel, the spread of invasive species, particularly arboviruses, have only increased in frequency and severity (Adeleke et al., 2010). 
DENV is known to be the most rapidly spreading mosquito-borne viral disease in the world. In the last 50 years, its incidence has increased 30-fold with increasing geographic expansion to new countries and from urban to rural settings (WHO, 2009). An estimated 50 million dengue infections occur annually with over 2.5 billion people living in dengue endemic countries (WHO, 2008). In recent years, dengue fever has been documented in travelers returning from several West African countries (Franco et al., 2010). In Nigeria, DENV IgM seroprevalences of 30.8\% (Faneye et al., 2013) and 17.2\% (Oladipo et al., 2014) were reported. Further study showed prevalence rates of 35\% and 73\% (Oyero and Ayukekbong, 2014.

Secondly, twenty five countries within the sub-Saharan region are now endemic to yellow fever virus infection (Jentes et al., 2011). In the last decade, the number of West African countries reporting yellow fever to World Health Organization (WHO) has increased, with 93\% of the countries notifying cases in the past 4 years. This is a 30\% increase compared to the period between 1995 and 1999 (WHO, 2014).

Thirdly, West Nile virus (WNV) infection has been reported in USA, Europe and few countries in Africa (Karabatos, 1985; Peiris and Amerasinghe, 1994; Hubalek and Halouzka, 1996). In 2013, a total of 2,469 WNV cases including 1,267 (51\%) neauroinvasive cases were reported from 725 counties in 47 states in the USA alone (Lindsey et al., 2014). Few data on WNV infection in sub-Saharan Africa is due to lack of sustained surveillance activities (Cabre et al., 2006).

These data are consistent with the fact that Flaviviruses are endemic and emerging infection in Nigeria. However, the diseases are neglected, under recognized and under reported in Nigeria, particularly Ogbomoso. Hence, this study was designed to identify some arboviral causes of fever in patients attending hospitals in a rural and semi-urban center in sub-Saharan African country. This is in order to ascertain the current epidemiological situation and provide information to clinicians to enhance patient care.

\section{Materials and Methods}

Study Design: Ninety-three plasma samples were tested from people between 1-75 years of age in Ayedaade (urban) area of Ogbomoso North Local Government area (LGA) and Otamokun village of Ogo Oluwa LGA in Oyo State. Recruited individuals enrolled from urban and rural areas were 47 (50.5\%) and $46(49.5 \%)$ respectively. There were 56 females and 37 males. Of this, 24 (25.8\%) were single and 69 (74.2\%) married.

Laboratory diagnosis: Commercial IgM ELISA kits for Dengue, West Nile and Yellow Fever were obtained from WKEA MED SUPPLIES CORP (Changchun, China) and stored at $2-8^{\circ} \mathrm{C}$. Assay procedure was carried out according to the manufacturer's specifications. Plates were labeled appropriately leaving two wells each on the last column for positive control, negative control and blank. $40 \mu 1$ of sample diluents was then added to $10 \mu \mathrm{l}$ of sample in each labeled well. It was carefully mixed and incubated at $37{ }^{\circ} \mathrm{C}$ for 30mins. Wash buffer was prepared by diluting it 50 times before washing five times using a plate washer (Biotek ${ }^{@}$ USA). $50 \mu$ l of enzyme conjugate was then added to all wells except the blank well and incubated at $37^{\circ} \mathrm{C}$ for $30 \mathrm{mins}$ as described above. Another round of washing was done for five times. $50 \mu \mathrm{l}$ each of chromogenic substrate $\mathrm{A}$ and $\mathrm{B}$ were then added and incubated in a dark room at $37^{\circ} \mathrm{C}$ for $15 \mathrm{mins}$. $50 \mu \mathrm{l}$ of stop solution was then added to each well and a colour change was observed from blue to yellow. Optical density was measured using a spectrophotometer with wavelength set at $450 \mathrm{~nm}$. The 
presence or absence of dengue, West Nile and yellow fever virus IgM was determined by comparing the sample absorbance with the absorbance of the cut-off calibrator.

\section{Statistical analysis}

Information from questionnaire was entered into an excel spreadsheet and analyzed using SPSS 16.0.

\section{Results}

Forty-nine (52.7\%) of the 97 sera were positive for DENV, WNV and YFV infections. Out of the 49 (52.7\%) IgM positive patients, $16(17.2 \%)$ were positive for DENV, 17 (18.3\%) for WNV and 16 (17.2\%) for YFV (Fig. 1). Gender analysis of the positive samples showed higher prevalence among females than males (Table 1). High prevalence were recorded in the age groups 16-30, 31-45 and 61-75 years in the age distribution of IgM positivity (Table 2). The result also shows that patients from the urban settings had more of the infections than those in the rural areas, however, for YNF, higher prevalence was found in the rural area (Fig. 2). Fig. 3 shows the prevalence of dual and trio arboviral infection.

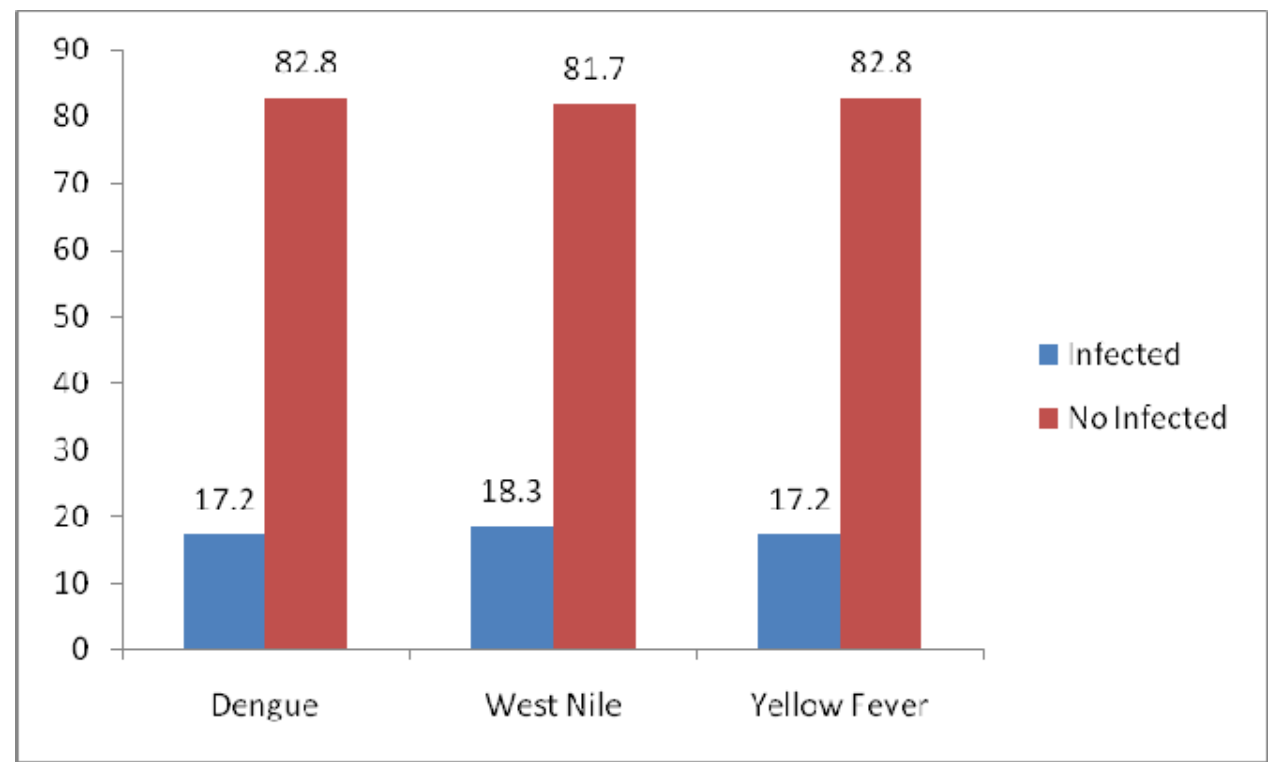

Fig 1. Distribution of individuals infected by DENV, WNV and YFV in the general population.

Table 1. Sex distribution of IgM positive individuals

\begin{tabular}{|l|l|l|l|}
\hline Sex/Infection & DENV IgM+ & WNV IgM+ & YFV IgM+ \\
\hline MALE & $7(43.8 \%)$ & $7(41.2 \%)$ & $6(37.5 \%)$ \\
\hline FEMALE & $9(56.2 \%)$ & $10(58.8 \%)$ & $10(62.5 \%)$ \\
\hline
\end{tabular}


Table 2. Age distribution of IgM positive people

\begin{tabular}{|l|l|l|l|}
\hline Age $(\mathbf{y r s})$ & DENV IgM+ & WNV IgM+ & YFV IgM+ \\
\hline $1-15$ & $2(12.5 \%)$ & $2(11.8 \%)$ & $2(12.5 \%)$ \\
\hline $16-30$ & $4(25.0 \%)$ & $5(29.4 \%)$ & $4(25.0 \%)$ \\
\hline $31-45$ & $6(6.5 \%)$ & $5(29.4 \%)$ & $5(31.3 \%)$ \\
\hline $46-60$ & $3(18.8 \%)$ & $4(23.5 \%)$ & $1(6.3 \%)$ \\
\hline $61-75$ & $1(6.3 \%)$ & $1(1.1 \%)$ & $4(25.0 \%)$ \\
\hline Total & $16(17.2 \%)$ & $17(5.9 \%)$ & $16(17.2 \%)$ \\
\hline
\end{tabular}

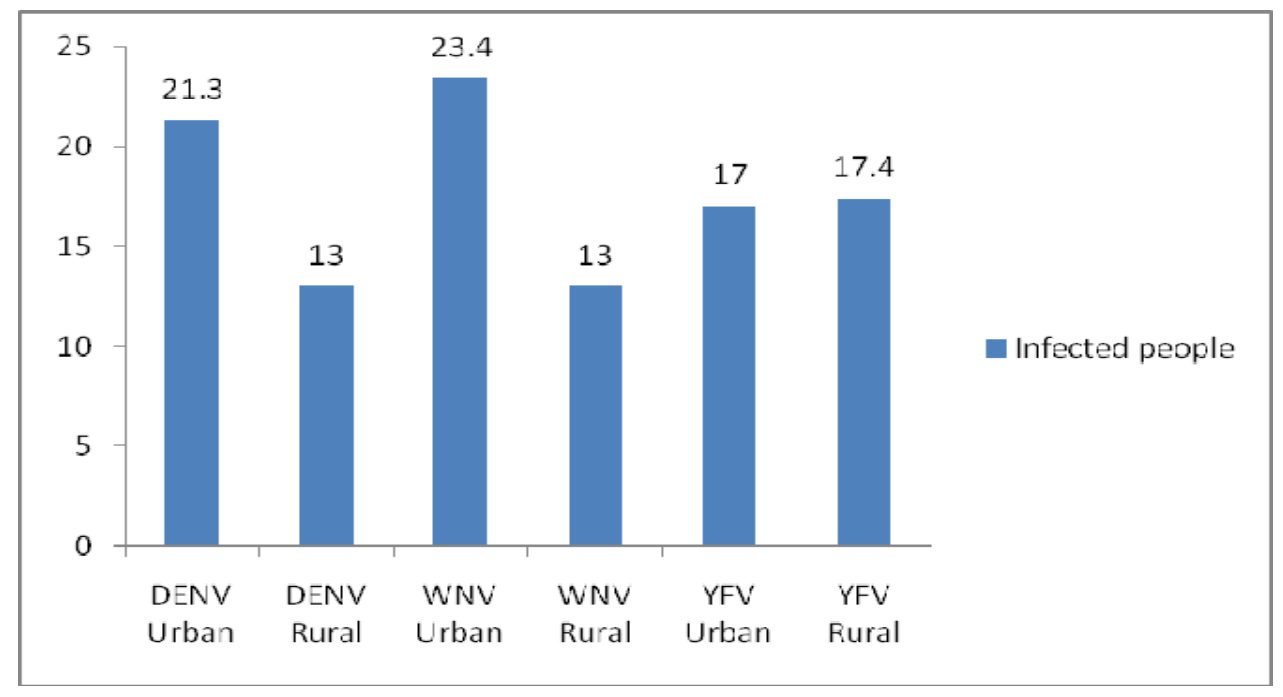

Fig 2. Distribution of proportion of infected people in rural and urban areas. 


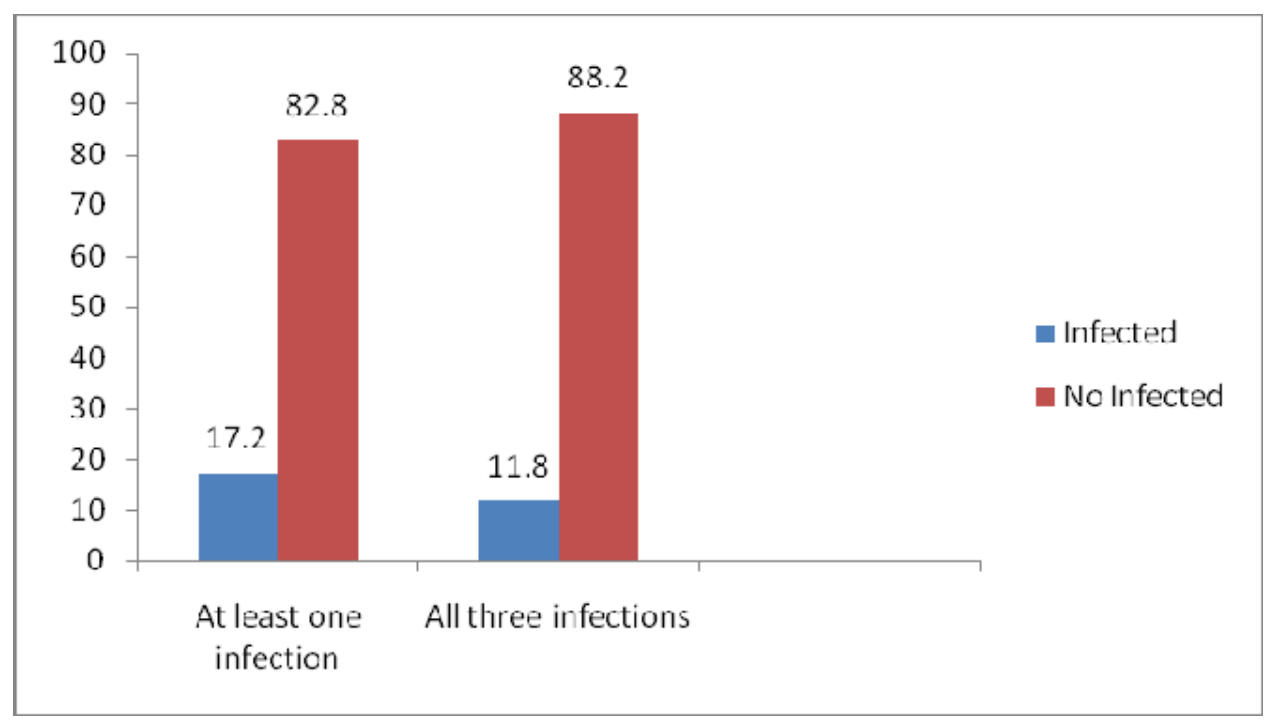

Fig 3. Distribution of individuals with dual or trio arboviral (DENV, WNV and YFV) infections

\section{Discussion}

Mosquitoes live with us in the habitat that we create. However, different land use establishes a range of habitats that can vary in quality and suitability for these mosquitoes. Human movement will continue to circulate vectors and pathogens. Throughout much of human evolutionary history, people have introduced exotic species into new geographic regions.

Epidemics of Flaviviruses have been documented throughout Africa over several decades. The spread of these viruses are limited by the presence of the mosquito vector which is found in tropical and subtropical climatic zones. Diseases caused by flaviviruses are the next most common tropical arthropod borne disease after malaria. This is more worrisome because of the presence of the vector in rural settings as well as urban cities (WHO, 2014).

The occurrence of arbovirus infections is an indication of the competence of mosquitoes. Although epidemics have not been identified in the study area, yellow fever epidemics occurred in Ogbomosho in 1946 and in Eastern Nigeria in 1951-53 (MacNamara, 1954). In 1987, there were epidemics of yellow fever in many parts of Southwestern Nigeria (Ogbomoso inclusive), which prompted mass vaccination of millions of Nigerians in the late 90s and stopped because of financial reasons but continued in 1997.

In sub-Saharan Africa, surveillance data for arboviral diseases is scanty, routine testing is not done and misdiagnosis is common because patients do not present with classical symptoms. In tropical countries there is increased hospitalization due to febrile illnesses which were initially suspected to be malaria or typhoid fever (Baba et al., 2006).

In this study, an overall prevalence of $52.7 \%$ (49/93) from the recruited individuals. Out of the 49 (52.7\%) IgM positive patients, 16 (17.2\%) were positive for DENV, 17 (18.3\%) for WNV and 16 (17.2\%) for YFV. The prevalence recorded for DENV is higher than $0.5 \%$ prevalence recorded at Maiduguri (Baba and Talle, 2011). The result obtained is lower than the prevalence rates of 30.8\% 
(Faneye et al., 2013), 35\% and 73\% (Oyero and Ayukekbong, 2014). The result is the same with the result obtained in Ogbomoso (Oladipo et al., 2014). The 18.3\% prevalence obtained for WNV is lower than a $44 \%$ prevalence obtained by Fagbami (1977) at Igbo-Ora. The result (17.2\%) obtained for YFV is lower than 36\% prevalence obtained at Igbo-Ora (Fagbami, 1977). The disparity in the results might be due to differences in the specificity of the serological tests used, sample size and the period when the studies were carried out.

High prevalence were recorded in the age groups 16-30, 31-45 and 61-75 years in the age distribution of IgM positivity. This is in accordance with the findings of Oladipo et al., (2014) that reported high prevalence among age groups 16-30 and 31-45 years which are within the age range of this study.

Gender analysis of the positive samples showed higher prevalence among females than males. This is consistent with the previous observations in Mexico (Kaplan et al., 1983). However, it disagrees with the findings of Awando et al., (2013) and and Oladipo et al., (2014). The difference might be as a result of difference in sample size.

The result also shows that patients from the urban settings had more of the infections than those in the rural areas, however, for YNF, higher prevalence was found in the rural area. This is consistent with the findings of Collenberg et al., (2006) and Oladipo et al., (2014) that the prevalence of DENV was higher in urban settings than rural settings in Burkina Faso. This statement cannot be generalized because of the difference in sample size and testing methods.

The prevalence of dual and trio arboviral infection showed $17.2 \%$ and $11.8 \%$ respectively. Co-infections of arbovirus has been reported in Nigeria (Baba et al., 2012). Co-infections have been found to provide opportunity for genetic materials exchange and mutations resulting in the emergence of strains with enhanced disease severity (Ayukekbong, 2014).

In conclusion, the result obtained confirms the circulation of Flaviviruses in Ogbomoso. There should be proper diagnosis of these infections and public awareness on effective vector control.

\section{References}

Kaufui V.W. (2017). Dengue fever, Yellow fever, West Nile and Zika viruses spread by mosquitoes and people worldwide. SF J Virol. 1:1.

Chisom E.O., Idris A.N., Kabiru M., Clinton N.C. (20170. Implications of flaviviruses cross-reactivity and vaccination programs on their serodiagnosis. N Y Sci J. 10(2):19-22.

Baba M.M., Talle M. (2011). The effect of climate on dengue virus infections in Nigeria. N Y Sci J. $4(1): 28-33$.

Ayukekbong J.A. (2014). Dengue virus in Nigeria: current status and future perspective. British Journal of Virology. 1(3):106-111.

Faneye A., Idika N., Motayo B.O., Adesanmi A., Afocha E. (2013). Serological evidence of recent dengue virus infection among febrile children in a semi arid zone. Am J Infect Dis. 9:7-10. 
Oladipo, EK, Amanetu C, Gbadero TA, Oloke JK. 2014. Detectable anti-dengue virus IgM antibodies among healthy individuals in Ogbomoso, Oyo state, Nigeria. Am. J. Infect. Dis. 10 (2):64-67.

Oyero, O. G., and J. A. Ayukekbong. 2014. High dengue NS1 antigenemia in febrile patients in Ibadan, Nigeria. Virus research 191: 59-61.

Awando J.A., Ongus J.R., Ouma C., Mwau M. (2013). Seroprevalence of anti-dengue virus 2 serocomplex antibodies in out-patients with fever visiting selected hospitals in rural parts of western Kenya in 2010-2011: a cross sectional study. Pan African Medical Journal. 16:73.

Kaplan, JE, et al. (1983). Epidemiologic investigations of dengue infection in Mexico, 1980. Am J Epidemiol. 117(3):335-43.

Fagbami A. (1977). Epidemiological investigations on arbovirus infections at Igbo-Ora, Nigeria. Trop Georg Med. 29(2):187-91.

Collenberg E, Quedraogo T, Ganamé J, Fickenscher H, Kynast-Wolf G, Becher H, et al.(2006). Seroprevalence of six different viruses among pregnant women and blood donors in rural and urban Burkina Faso: a comparative analysis. J Med Virol. 78:683-92. doi:10.1002/jmv.20593

Lindsey NP, Lehman JA, Staples JE, Fischer M. (2014). West Nile Virus and other arboviral diseases United States, 2013. MMWR. 63(24):521-6

Franco L, Di Caro A, Carletti F, Vapalahti O, Renaudat C, Zeller H, Tenorio A. (2010). Recent expansion of dengue virus serotype 3 in West Africa. Euro Surveill. 15(7):1-4.

Cabre O., Grandadam M., Marié J-L., Gravier P., Prangé A., Santinelli Y., Rous V., Bourry O., Durand JP., Tolou H., and Davoust B. (2006). West Nile Virus in Horses, sub-Saharan Africa. Emerg Infect Dis J. 12(12):1958-60

Karabatsos N, editor (1985). International catalogue of arboviruses, including certain other viruses of vertebrates.3rd ed., and Supplements 1986-98. San Antonio: American Society of Tropical Medicine and Hygiene5.

Peiris JSM, Amerasinghe FP. (1994). West Nile fever. In: Beran GW, Steele JH, editors. Handbook of zoonoses. Section B: Viral. 2nd ed. Boca Raton (FL): CRC Press; p. 139-48.

Hubálek Z, Halouzka J. (1996). Arthropod-borne viruses of vertebrates in Europe. Acta Scientiarum Naturalium Brno. 30(4-5):1-95.

WHO (2014). Increased risk of urban yellow fever outbreaks in Africa. http://www.who.int/csr/disease/yellowfev/urbanoutbreaks/en/

Jentes ES. Poumerol G, Gershman MD, et al. (2011). The revised global yellow fever risk map and recommendations for vaccination, 2010: consensus of the Informal WHO Working Group on Geographic Risk for Yellow Fever. Lancet Infect Dis. 11:622-32. 
Monath, T.P. (1994). Dengue: The risk to developed and developing countries. Proc. Nat. Acad. Sci. USA. 91: 2395-400.

Carey D.E., Kemp G.E., Troup J.M., White H.A., Smith E.A.,Addy R.F., Fom A.L., Pifer J. Jones E.M., Brls P. and R.E. Shope R.E. (1972). Epidemiological aspects of the 1969 yellow fever epidemic in Nigeria. Bull. Wld Hlth. Org. 46:645-651

Adeleke M.A., Mafiana C.F., Idowu A.B., Sam-Wobo S.O., Idowu O.A. (2010). Population dynamics of indoor sampled mosquitoes and their implication in disease transmission in Abeokuta, South-western, Nigeria. J. Vector Borne Dis., 47:33-38.

World Health Organization (2008). Dengue and dengue haemorrhagic fever. Factsheet No 117, revised May 2008. Geneva, 2008 (http://www.who.int/mediacentre/factsheets/fs117/en/).

Nathan M.B. and Dayal-Drager R. (2007). Recent epidemiological trends, the global strategy and public health advances in dengue. Working paper 3.1 in: Report of the Scientific Working Group meeting on Dengue, Geneva, 1-5 October 2006. Geneva, World Health Organization, Special Programme for Research and Training in Tropical Diseases pp 29-34.

Kokernot RH, Smithburn KC, Weinbren MP. (1956). Neutralising antibodies to arthropod-borne viruses in human and animals in the Union of South Africa. Journal of Immunology. 77:313-322.

Blackburn NK, Rawal R. (1987). Dengue fever imported from India: a report of 3 cases. South African Medical Journal. 21:386-287. 